\title{
PRÁTICAS SOCIODISCURSIVAS DE RESISTÊNCIA MOTIVADAS PELA ITERABILIDADE DE VIOLÊNCIAS: ANÁLISE DISCURSIVO-CRÍTICA DOS RELATOS DE HOMENS TRANS ESTUDANTES
}

\author{
SOCIO-DISCURSIVE RESISTANCE PRACTICES \\ MOTIVATED BY THE ITERABILITY OF VIOLENCE: \\ CRITICAL DISCOURSE ANALYSIS OF TRANS \\ MEN STUDENTS' REPORTS
}

\section{Samuel de Sá Ribeiro* Maria Carmen Aires Gomes*}

\begin{abstract}
RESUMO
A partir dos relatos de homens trans estudantes de uma escola pública brasileira, analisamos as práticas sociodiscursivas de resistência produzidas por eles principalmente na esfera educacional, mas também no âmbito familiar. Para tanto, nossa pesquisa discursivaetnográfica vincula-se teórica e metodologicamente à Análise de Discurso Crítica de vertente anglo-saxã, empreendida por Norman Fairclough e Lilie Chouliaraki, que tem propriedade transdisciplinar. A fim de produzir uma crítica-explanatória, articulamos a análise linguísticodiscursiva dos dados semióticos aos Estudos de Gênero. Nas narrativas, observamos identificações e representações de práticas violentas que banalizam o reconhecimento e as necessidades particulares dos corpos trans estudantes promovendo opressões que emergem a partir da combinação de diferentes eixos da diferença, como o gênero e a raça. Essas interpelações violentas motivam esses agentes sociais a reagirem discursivamente em meio à vida social potencialmente cis-heteronormativas e normalizadora.

Palavras-chave: análise de discurso crítica; homens trans estudantes; práticas de resistência.
\end{abstract}

\section{ABSTRACT}

From the reports of transgender men students from a Brazilian pubic school, we analyzed the socio-discursive practices of resistance produced by them mainly in the educational sphere, but also in the family sphere. Therefore, our discursive-ethnographic research is theoretically and methodologically linked to the Critical Discourse Analysis of an AngloSaxon origin, which is a transdisciplinary approach undertaken by Norman Fairclough and Lilie Chouliariaki. In order to produce an explanatory-critical, we articulate the linguistic and

\footnotetext{
* Universidade Federal de Viçosa, UFV, Viçosa, MG, Brasil. samuelsaribeiro@gmail.com Orcid: https://orcid.org/0000-0003-4476-8129

** Universidade Federal de Viçosa, UFV, Viçosa, MG, Brasil. mcgomes@ufv.br Orcid: https://orcid.org/0000-0001-7402-4353
} 
discursive analysis of the semiotic data to Gender Studies. In the narratives, we have noticed identifications and representations of violent practices that trivialize the recognition and the particular needs of trans students' bodies promoting oppressions that emerge from the combination of different axes of difference, such as gender and race. These violent questions motivate these social agents to react discursively amid potentially cis-heteronormative and normalizing social life.

Keywords: critical discourse analysis; transgender men students; resistance practices.

\title{
CONSIDERAÇÕES INICIAIS
}

\author{
Eu sou resistência. \\ Transcender a alma, elevar a força, \\ dar resistência ao corpo, um espírito \\ que não se deixa levar no mar morto \\ chamado sociedade. \\ Eu luto! \\ Eu sobrevivo! [...] \\ Luan Bressanini (Antologia Trans)
}

Os versos de Bressanini, homem trans brasileiro, fazem referência às experiências das vivências trans em uma sociedade marcada por regulações sociais cis-heteronormativas e parcialmente afetada por ideologias ultraconservadoras que não raramente são tomadas como base para violentar corpos LGBTQI+. É dessa vivência violenta que emerge a luta, a resistência.

Pesquisas recentes têm analisado as vivências transmasculinas em diferentes esferas da vida social, como no contexto familiar e na saúde pública (ALMEIDA, 2012; PEDRINI, 2017). Ao observar estudos sobre gêneros, sexualidades e violências, com enfoque na educação (CRUZ, 2011; SALES, 2012; CICILLINI; FRANCO, 2016), constatamos que poucos eram os estudos discursivos que discutiam as vidas transmasculinas no âmbito das práticas educacionais e, por isso, nos perguntamos: como bomens trans estudantes experienciam a vida escolar e resistem às contestações de suas identidades transmasculinas nessa instituição bistoricamente conservadora? Isso porque práticas socioescolares podem tanto produzir violências de gênero quanto acolher estudantes trans, a depender do tempo-espaço em que são constituídas e dos agentes sociais (suas crenças e ideologias) envolvidos nas relações sociais.

Neste artigo, analisamos as práticas socioescolares de uma escola pública brasileira, localizada no município de Viçosa, interior de Minas Gerais ${ }^{1}$, a partir das quais dois homens trans relataram a vida escolar e a forma como produziram

1. O estudo apresentado neste artigo é um recorte da pesquisa que tinha como objetivo analisar as identificações e representações produzidas por homens trans estudantes de duas escolas públicas localizadas na cidade de Viçosa, Minas Gerais - Brasil. 
ações e práticas sociodiscursivas de resistência em relação às regulações cisheteronormativas. Este estudo de base etnográfica ocorreu no ano de 2019 em meio a uma conjuntura sociopolítica brasileira que tem um governo cujo conceito de família assume uma centralidade discursivo-ideológica de cunho conservador e de extrema-direita, que nega, entre tantas outras questões, a pauta do gênero.

A partir da perspectiva discursivo-crítica, nossos objetivos neste artigo são descrever, interpretar e explanar as práticas discursivas de resistência produzidas por homens trans estudantes no enfrentamento às negligências da instituição escolar em relação às suas identidades e demandas particulares. O estudo vincula-se teórica e metodologicamente à Análise de Discurso Crítica (ADC) de vertente anglosaxã (CHOULIARAKI; FAIRCLOUGH, 1999; FAIRCLOUGH 1992; 2003), à proposta de Gomes (2020), sobre a ADC Generificada, e aos Estudos de Gênero (BENTO, 2011; ALMEIDA, 2012; CONNELL; 2013; BUTLER, 2015, 2016, 2018; LUGONES, 2014; OLIVEIRA, 2015; COLLINS, 2017; BUENO, 2019).

A escolha do objeto discursivo "relatos de homens trans estudantes" está atrelada ao fato de que esses agentes sociais performatizam masculinidades plurais (ÁVILA, 2014) e interseccionadas que mobilizam alguns eixos do poder (privilégios e opressões), o que interessa às investigações linguístico-discursivas críticas. Nesse sentido, Connell e Messerschmidt (2013) argumentam que as masculinidades são hierarquizadas socialmente em relação a um padrão hegemônico de referência - o cisgênero, possuidor de um pênis (falo). Assim, os homens trans podem ser considerados, de modo não generalizante, como corpos menos hegemônicos em relação àqueles. São corpos que tensionam as normas de sexo-gênero; são geralmente - homens de vagina, sem o poder do falo.

Oliveira (2015), pesquisador e homem trans brasileiro, assim como Salabert (2019), ativista brasileira e travesti, defendem que o falo, enquanto poder, está no campo da masculinidade, mas da masculinidade cisgênera, a qual aquele elemento corpóreo é dado naturalmente. Reconhecemos, dessa forma, o potencial da hierarquização das masculinidades para a produção de corpos 'ininteligíveis' e subalternos, como alguns corpos transmasculinos. Sob essa perspectiva e a partir das escolhas lexicogramaticais (HALLIDAY; MATHIESSEN, 2004) materializadas nos relatos dos homens trans estudantes colaboradores deste estudo, analisamos as relações de poder, as violências e as ações de resistência identificadas e representadas por eles nos discursos que produzem sobre a vida escolar.

Inicialmente, será apresentada a proposta de ADC Generificada elaborada por Gomes (2020); no segundo momento, os procedimentos metodológicos empreendidos. Na sequência, abordamos a iterabilidade de violências na conjuntura 
escolar analisada como fator propulsor para práticas sociodiscursivas de resistência. Por fim, desenvolvemos a análise de tais práticas materializadas nos relatos dos homens trans estudantes seguida da explanatória crítica.

\section{ANÁLISE DE DISCURSO CRÍTICA GENERIFICADA (ADCG)}

A ADC Generificada é uma proposta teórico-metodológica guiada pelas premissas e princípios desenvolvidos pelos estudos discursivos críticos de base anglo-saxã, que se fundamenta em uma ontologia realista para se pensar na constituição da vida social (GOMES, 2020). Barros, Vieira e Resende (2016, p. 12) afirmam que "a vida é compreendida como um sistema aberto, governado por mecanismos oriundos das estruturas das quais resultam os eventos sociais.", sendo que ambos (estruturas e eventos) fazem parte da realidade social e estabelecem entre si um tipo de relação transformacional. No âmbito da Análise Discursiva Textualmente Orientada (ADTO), abordagem a que se baseia a ADC generificada, para Chouliaraki e Fairclough (1999), Fairclough (2003) e Fairclough e Fairclough (2012), a vida social é analisada e conceitualizada como uma ação dialética e transformacional entre três níveis da realidade social: estruturas e eventos, ambos mediados pelas práticas, que são relativamente estáveis (e duráveis). Neste sentido, "o mundo social é constituído de redes de práticas articuladas" (RESENDE, 2009, p. 30), que se associam umas às outras produzindo uma rede interconectada de elementos: discurso, relações sociais, fenômeno mental e atividade material. Tais elementos, também compreendidos como momentos da prática social, estão em relação dialética de interiorização em que "cada qual contém ou internaliza o outro - relações sociais são parcialmente discursivas em sua natureza, o discurso é parcialmente constituído de relações sociais" (RESENDE, 2009, p.30).

O conceito de práticas sociais, então, se torna determinante uma vez que elas

definem modos particulares de ação e, embora eventos realizados possam divergir mais ou menos dessas definições e expectativas (porque eles atravessam diferentes práticas sociais e por causa dos poderes causais de agentes sociais), eles ainda são parcialmente moldados por elas (FAIRCLOUGH, 2003, p. 25).

Os poderes causais são compreendidos de modo contingencial, no sentido de que a causalidade não implica regularidades. Um determinado evento pode ser dito como causa de outro, mas não será sempre possível e coerente afirmar o acarretamento de uma correlação regular desses eventos - "isso porque efeitos têm múltiplas causas que afetam uma operação e outra" (BARROS, 2015, p. 66). Fairclough (2003) 
considera que os poderes causais constrangem tanto os eventos quanto os textos e eles se dividem em dois: (i) a estrutura social e a prática social (ii) agentes sociais - pessoas engajadas nos eventos. (ARCHER, 1995; SAYER 2000). Na conjuntura desta pesquisa, a instituição escolar, a família e a religião podem ser consideradas estruturas (instituições sociais) que atuam em práticas socioescolares por meio de discursos investidos de poderes ideológicos e causadores de obstruções, de fechamento para a vivência de homens trans estudantes (Cf. RIBEIRO, 2020).

O discurso, nesta proposta discursivo-crítica, é o elemento semiótico da prática social; um dos momentos da prática social, a qual é constituída simultaneamente por práticas discursivas e por elementos não discursivos que não se reduzem entre si. Fairclough (2003, p.3) reitera: "o discurso é um momento irredutível da vida social, dialeticamente conectado a outros elementos." Os elementos não discursivos (CHOULIARAKI; FAIRCLOUGH, 1999) são atividades materiais, relações sociais e fenômeno mental (crenças, valores, ideologias). É nesse cenário ontológico e dialético, portanto, que se relacionam discurso, ação e vida. Essa ontologia discursiva que coloca as práticas sociais no epicentro da transformação social se alinha à forma como Connell (2013, p. 17), no âmbito dos estudos de gênero, compreende a fundamental relação também entre corpo e prática social: "práticas sociais envolvem mãos que fazem, olhos que observam, peles que sentem, cérebros que raciocinam e sofrem". Connell (2013), ao definir gênero como estrutura, coloca na prática social a "origem" da produção, reprodução ou iteração de nossas formas de olhar para o gênero, porque são nas interações e relações sociais, em espaços e tempos específicos, a partir de nossas crenças, valores, experiências e vivências, que discursos e conhecimentos são (re)produzidos, iterados. Isso porque "as práticas sociais não acontecem sem corpos" (CONNELL, 2013, p.17).

Nessa perspectiva, Gomes (2020, p.52) afirma que "discursos produzidos em certas práticas sociais são o resultado dessa rede de processos introjetados na dinamicidade do gênero que tem o corpo como a "principal arena de incidência" dessa dinâmica (MOSCHKOVICH, 2016, p. 12). A partir das ideias de Connell (2013) e de Chouliaraki e Fairclough (1999), Gomes (2020) inclui o elemento corpo na constituição da prática social: 


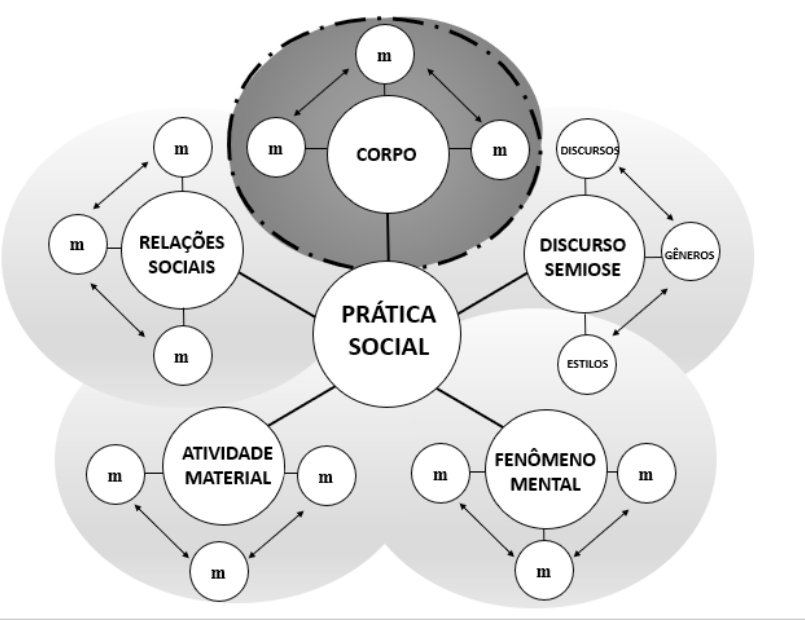

Figura 1. Corpo como um dos momentos da prática social Fonte: Gomes $(2020$, p.85)

Metodologicamente, a ADC Generificada toma como ponto de partida a inclusão do Corpo como um dos elementos da prática social que se corporifica a partir do movimento dialético e articulatório que se realiza com os outros elementos, produzindo momentos discursivos distintos. A maneira como o corpo se corporifica socialmente tem a ver com a forma pela qual se internaliza e se articula com os outros elementos, potencializando-se, de maneira produtiva, criando novos discursos, novos olhares sobre a (des) ordem social.

A inclusão do corpo possibilita problematizar as ontoformatividades, que se constituem em uma (des)ordem de gênero, isto é, uma estrutura em si, um sistema político estruturante e organizado por dispositivos jurídicos, religiosos, biológicos, identitários. A ontoformatividade é "um processo que gera, a cada momento, novas realidades históricas: novas possibilidades corporificadas, experiências, limitações e vulnerabilidades para as pessoas envolvidas." (CONNELL, 2016, p. 49). Connell acrescenta: é o "poder de criar realidades sociais ao longo do tempo histórico" e deve-se ao fato de as estruturas sociais estarem sempre em processo de construção, iteração, contradição, transformação e atualização.

Esse (des)ordenamento político e estruturante é operado, nas práticas sociais, por dispositivos que funcionam simultaneamente sobre as pessoas, de maneiras diferentes, causando efeitos ontoformativos distintos. Nas práticas sociais, fazemos escolhas (ou somos restringidos, constrangidos) não só da ordem da materialidade semiótica (estilos, discursos e gêneros), mas também dos dispositivos que operam produtivamente nos corpos/discursos - como os dispositivos: racialidade, patriarcado, 
pedagógico, biomédico, religioso e outros mais que disseminam e difundem seus poderes sobre as mais variadas existências em nossa sociedade (Cf. GOMES, 2020).

$\mathrm{Na}$ ADC Generificada, o corpo é compreendido como corpo/discurso protagonista, ativo, que se transforma, performa, experiencia, sente prazer, sofre e se rebela - tal concepção parte das proposições de Butler (2018) sobre agentividade dos corpos. O corpo, nesta abordagem, leva em consideração a dimensão analítica, política e epistêmica interseccional que permite perceber como ocorre a corporificação numa dada prática social, já que visibilizará os variados aspectos do poder, muitas vezes, "invisíveis", principalmente, para as pessoas que pertencem ao eixo dos privilégios. Essa teoria do conhecimento permite-nos entender que o corpo, como um dos elementos da prática social, se corporifica diferentemente a partir da colisão dos eixos de poder (privilégio e opressão): Gênero, Raça, Etnia, Classe Social, Territorialidade- espacial geográfica, Tamanbo, Capital intelectual, Deficiência, Faixa etária. Segundo Bueno (2019), a interseccionalidade é hoje um conceito em disputa: para uns, se define como uma ferramenta analítica, para outros, como um método, e para muitas intelectuais negras, como um projeto de conhecimento, que surge antes mesmo do documento produzido por Kimberlé Crenshaw (2002), no qual a pesquisadora desenvolveu o termo interseccionalidade. Para Collins (2017), Bueno (2019), Akotirene (2018), o que se conceitua por interseccionalidade, nos termos de Crenshaw, surge muito antes e deve-se sobretudo aos esforços empreendidos pelos movimentos sociais, pelo ativismo negro, principalmente nos EUA.

Para Bueno (2019, on-line): "não é uma mera categoria conceitual, é uma perspectiva histórica de luta que nem sempre foi assim nomeada, de afeto e de encontros intergeracionais mobilizados pelo respeito, pelo reconhecimento e sobretudo pelo amor que construímos a partir de relações cunhadas nos espaços seguros mobilizados por mulheres negras." Assim que a interseccionalidade é uma epistemologia de mulheres negras compromissadas com a justiça social, e que tem a sua genealogia no ativismo negro e se define como uma teoria do conhecimento e da ação política, ou seja, um projeto de resistência que objetiva a mudança de paradigmas na construção dos saberes, dos poderes e da existência. Apesar de os estudos interseccionais terem focalizado com mais frequência as vulnerabilidades interseccionais das mulheres racializadas, reconhece também que, "ocasionalmente, homens são marginalizados" (CRENSHAW, 2002, p.178), como ocorre com alguns homens trans, foco deste estudo.

Para Collins (2017, p.7), a interseccionalidade "pode ser vista como uma forma de investigação crítica e de práxis, precisamente, porque tem sido forjada por ideias de políticas emancipatórias de fora das instituições sociais poderosas, assim 
como essas ideias têm sido retomadas por tais instituições" (COLLINS, BILGE, 2016). O corpo interseccionado será analisado aqui, conforme Bueno define a interseccionalidade:

enquanto um conjunto de ideias e práticas que sustentam que gênero, raça, classe, sexualidade, idade, etnia, status de cidadania e outros marcadores não podem ser compreendidos de forma isolada, sendo que estes articulam dinâmicas de poder que produzem realidades materiais desiguais e experiências sociais distintas coletiva e individualmente (BUENO, 2019, on-line).

Trazer a dimensão analítica interseccional para o estudo do corpo implica dizer, por exemplo, que, em uma prática socioescolar, um corpo colidido transhomem gordo, negro e periférico altera as dinâmicas das relações sociais entre colegas e profissionais da escola, gerando novos discursos particulares a partir de valores, crenças e ideologias; mas também podem ser mantidos discursos racistas, gordofóbicos, cis-heteronormativos. Assim que o corpo interseccionado ajuda a visualizar a forma como os poderes se articulam à luz de uma matriz de dominação permitindo compreender como essas experiências se constituem e são constituídas pelos eixos do privilégio e da opressão. A vivência e experiência complexa deste corpo interseccionado vai além do reconhecimento dos vários eixos que ali colidem; esse corpo manifesta em sua complexa imbricação as subordinações, opressões e privilégios que experimenta. $\mathrm{Na}$ vida social, é possível perceber múltiplas performances transmasculinas experienciando a vida escolar de formas distintas e com vulnerabilidades também diferentes, ou seja, considerando a matriz de dominação (COLLINS, 2017), é possível compreender como os poderes estão se articulando, interagindo de forma a produzir certas experiências e vivências já que recaem sobre os corpos de maneiras distintas.

Antes de analisar os relatos produzidos pelos homens trans, os quais denunciam diferentes violências em práticas socioescolares e familiares, passemos à descrição do cenário em que este estudo se delineou e à apresentação da combinação das metodologias usadas tanto para obter os dados linguísticos quanto para analisálos.

\section{PERCURSOS METOdOLÓGICOS DA PESQUISA DISCURSIVA DE BASE ETNOGRÁFICA}

O presente estudo é qualitativo; de base etnográfica; interpretativoexplanatório e centrado teórica e metodologicamente na Análise do Discurso Crítica Generificada (ADCG) proposta por Gomes (2020) e nos Estudos de Gênero. 
A investigação discursiva-etnográfica que desenvolvemos buscou estabelecer um diálogo entre os princípios etnográficos de pesquisa qualitativa e a metodologia de análise empreendida crítica-explanatória de Chouliaraki e Fairclough (1999), embasada em Bhaskar (1989), a qual busca investigar problemas sociais, partindo da reflexão acerca de elementos semióticos e de seus potenciais efeitos ideológicos em práticas sociais particulares (Cf. RIBEIRO, 2020). A análise linguístico-discursiva segue o modo tridimensional, como Fairclough (1992) orienta: descrição, interpretação e explanação dos textos. Para a análise, foi usado ainda o Sistema de Avaliatividade (WHITE, 2004, p.177) para pensar que as materialidades semióticas são concebidas "não simplesmente como formas através das quais falantes/escritores individuais expressam seus sentimentos e posições", mas ainda como meio que possibilita pessoas a adotarem posições de valor determinadas social e culturalmente.

Em Estudos Discursivos Críticos, pesquisas de base etnográfica selecionam técnicas variadas de geração e coleta de dados. Esses recursos possibilitam a produção do material semiótico para análises discursivas textualmente orientadas. É a partir dessas realizações semióticas que são analisadas as redes de práticas discursivas constituídas na conjuntura em que são produzidas e articuladas - em nosso caso, na esfera educacional (Cf. RIBEIRO, 2020).

Os dados linguísticos foram gerados por meio de uma combinação de ferramentas: (i) questionário socioeconômico, (ii) entrevistas semiestruturadas com os estudantes trans e a (iii) observação dos espaços físicos da escola (salas de aula, banheiros, corredores e biblioteca), o que gerou a produção de (iv) notas de campo, as quais nos conduziram a uma autorreflexão acerca dos dados da pesquisa e possibilitaram a prévia interpretação deles (RESENDE, 2008).

As entrevistas com os estudantes ocorreram entre os meses de fevereiro e abril de 2019 e foram realizadas individualmente. Elaboramos um roteiro semiestruturado de questões abertas que levou em conta a possibilidade de inclusão de perguntas adicionais à medida em que a conversa ocorria (DUARTE, 2002). A princípio, inserimos questões acerca de quando se deu a autoidentificação com o gênero masculino e como vinha sendo esse processo na escola. Os estudantes foram questionados também sobre a exposição a situações transfóbicas, sobre a intervenção de professores/as nesses momentos, sobre as interações sociais com colegas e com as/os profissionais da educação em geral. Outro aspecto que o planejamento da conversa abordou foi o espaço físico da escola, com enfoque nos banheiros, locais tradicionalmente generificados. O nosso roteiro prévio não orientava para o diálogo sobre a vida trans na família, mas essa temática foi levantada espontaneamente pela maioria dos colaboradores. Com o material semiótico gerado 
e gravado em áudios, realizamos as transcrições integrais das entrevistas. Para saturar os dados e direcionar o percurso analítico do corpus, utilizamos o software Kit Conc 4.0 - um concordanciador desenvolvido pelo linguista José Lopes Moreira Filho -, que possibilitou a realização de uma análise inicial das recorrências linguísticas e a seleção dos trechos a serem analisados (Cf. RIBEIRO, 2020).

Os relatos dos estudantes trans que analisamos aqui são, como defende Butler (2015), relatos de si: narrativas afetadas pela cena de interpelação (condições de produção discursiva). Tais relatos possibilitam a análise da valoração de práticas sociais que ora denunciam violências nos âmbitos escolar e/ou familiar, ora evidenciam certas aberturas e /ou fissuras para o reconhecimento das diferenças (FAIRCLOUGH, 2003).

Apresentamos, a seguir, os estudantes Bear Lukas e Arthur da Escola João Nery $^{2}$ - eles, acreditando no potencial político e emancipatório deste estudo, participaram das entrevistas semiestruturadas individuais e compartilharam gentilmente parte de suas vivências nas práticas socioescolares da instituição. Os nomes reais foram mantidos tendo em vista o interesse dos estudantes e considerando a importância da representação verossímil das ontologias dos colaboradores de estudos etnográficos - o que já vem sendo discutido por pesquisadores da antropologia. Fonseca (2010, p.209) reflete: a omissão dos nomes verídicos "parece designar justamente as pessoas que têm algo para esconder". Ademais, "que coisas 'repreensíveis' estariam sendo contadas sobre os interlocutores [colaboradores] da pesquisa que incube o pesquisador de esconder as identidades deles?" (FONSECA, 2010, p. 210). Em função de questões éticas, o consentimento foi informado pelos colaboradores deste estudo discursivo-etnográfico para que os nomes verdadeiros fossem mantidos. O uso dos nomes reais produz "um acréscimo nada desprezível à verossimilhança de nosso material [semiótico] etnográfico" (FONSECA, 2010, p. 213). Essa escolha de prezar pelos nomes reais, quando possível, reconhece a importância deles para que não sejam perdidos preciosos traços ontológicos e semânticos do contexto pesquisado ${ }^{3}$. As descrições a seguir tomaram como base as respostas aos questionários de pesquisa e algumas partes dos relatos dos estudantes.

2. A escolha desse nome visa homenagear João Nery, que faleceu em 2018. Nery foi um importante ativista brasileiro, reconhecido por ter sido o primeiro homem trans a fazer a cirurgia de mamoplastia masculinizadora em pleno período ditatorial. Foi autor de livros que abordam a temática de gênero e de sua transmasculinidade, como Viagem Solitária e Velhice Transviada.

3. Nota de evento acadêmico: Essa discussão sobre a importância do uso dos nomes reais dos colaboradores de pesquisas etnográficas também foi desenvolvida mais recentemente na abertura da II Jornada Internacional de Linguística Aplica Crítica (JILAC), que ocorreu na Universidade de Brasília, em julho de 2019. 
Bear Lukas é um homem trans, heterossexual, autodeclara-se negro, tinha 18 anos no período em que nos relatou sua vida escolar. Esse nome tem relação com a interação de Bear com sua professora de História - ele disse à educadora que queria ter muitos pelos e, a partir disso, ela o nomeou de "urso". Foi assim que ele definiu seu nome social, optando pelo estrangeirismo "Bear", do inglês, urso. Ele iniciou o processo de hormonização por conta própria e sem acompanhamento médico, já que desejava ter pelos no corpo marcando sua masculinidade. Bear tem cabelos longos e alisados devido às exigências da mãe. Seu relato destaca-se em relação ao de Arthur porque demarca, com mais frequência, os dilemas familiares implicados pela religiosidade da figura materna (Cf. RIBEIRO, 2020).

Arthur é um homem trans, heterossexual, autodeclara-se pardo, tem cabelos longos e cacheados, também tinha 18 anos quando foi entrevistado. As alterações marcadas física e simbolicamente no seu corpo, até o momento das entrevistas, eram: o uso de roupas masculinas e a escolha do nome social masculino. Em seu relato, o estudante denuncia as opressões vivenciadas na escola e faz referência aos impasses familiares ativados por ideologias religiosas que são tomadas como referência para a deslegitimação e apagamento de sua existência trans (Cf. RIBEIRO, 2020).

\section{ITERABILIDADE DE VIOLÊNCIAS E PRÁTICAS SOCIODISCURSIVAS DE RESISTÊNCIA NA ESCOLA}

Violências contra a população trans são muitas vezes delineadas a partir da "produção normativa do sujeito, que é um processo de iterabilidade - as normas são repetidas", se naturalizam social e historicamente enquanto princípios morais e não raramente são tomadas como base para justificar e promover violências de sexogênero (BUTLER, 2018, p. 237). Para este estudo, violência é definida em relação ao conceito de poder:

está ligada à possibilidade de alguém impor sua vontade, sem consentimento, sobre a vontade do outro. Isso pode ser feito de diversas formas: por meio de agressão física, chantagem, pressão psicológica ou ataque moral - ou ainda impedindo que o outro exerça seus direitos. Originária do latim violare, a palavra violência também compreende, conforme sua raiz, a noção de violação (LINS, MACHADO; ESCOURA, 2016, n.p).

A linguagem tem papel importante não só na consolidação de normas sociais e na manutenção delas, mas também na produção e manutenção de violências. É por meio das redes de práticas sociodiscursivas que diferentes corpos recebem atribuições e identificações. Esses processos limitam comportamentos de determinados corpos não raramente de modo violento, o que afeta socioemocionalmente parte dos 
estudantes trans criando um clima desfavorável à aprendizagem e favorável à evasão escolar deles (NERY; GASPODINI, 2015; BENTO, 2011; MISKOLCI, 2009).

Os discursos produzidos por homens trans estudantes da Escola João Nery evidenciaram que eles experienciam o estranhamento e a deslegitimação de suas transmasculinidades, de maneira violenta, ao terem suas identidades negligenciadas e afrontadas. Foi da iterabilidade de práticas de opressão, mais notáveis ou mais opacas discursivamente, que emergiram as ações de resistência. Afinal, "a luta existe quando se está imerso na violência, assim surge a possibilidade da não violência" (BUTLER, 2018, p. 241; FAIRCLOUGH, 2003).

Lugones (2014), ao defender a resistência à colonialidade do gênero, evidencia o seu interesse em uma ética de coalizão-em-processo em termos de "sersendo" e de "ser-sendo-em-relação". Essa filósofa afirma que, enquanto teórica da resistência, não considera tal processo "como o fim ou meta da luta política, mas como seu começo, sua possibilidade". A resistência, portanto, está "na proliferação relacional subjetiva/intersubjetiva da libertação", que pode ser "adaptativa ou criativamente opositiva" (LUGONES, 2014, p. 939).

$\mathrm{O}$ que faz então emergir práticas sociodiscursivas de resistência? $\mathrm{O}$ ponto chave para essa indagação nos parece ser a identificação da origem de tensões que fomentam, em uma rede de práticas, ações sociodiscursivas engajadas em lutas contra hegemônicas. Assim, ao analisar discursivamente a resistência, torna-se crucial observar a seguinte questão: quais são os poderes causais que, nas palavras de Lugones, motivam ou "despertam a subjetividade ativa, o agenciamento necessário para que a relação opressão $\leftarrow \rightarrow$ resistência seja uma relação ativa?" (LUGONES, 2014, p.940; FAIRCLOUGH, 2003).

Lugones (2014, p. 939) argumenta que os efeitos da colonização estão presentes em nossa sociedade ainda hoje e devem ser observados interseccionalmente, ou seja, levando em conta a coexistência dos traços de gênero/classe/raça. De modo análogo, temos a historicidade das vulnerabilidades experienciadas pela comunidade LGBTQI+ no Brasil, grupo que é frequentemente vítima de ataques que patologizam, demonizam e desumanizam as diferentes identidades incluídas nesse acrônimo, como as vidas transmasculinas (ÁVILA, 2014; OLIVEIRA, 2015; FATIMA, 2018; RIBEIRO, 2020). Assim, diante desses conhecimentos sóciohistóricos, como podemos compreender as práticas sociodiscursivas de resistência?

Práticas sociodiscursivas de resistência podem ser compreendidas como manifestações semióticas em que agentes sociais externalizam as injustiças e indignações experienciadas na vida social. Elas são denunciativas de uma realidade estratificada, assombrada e assolada pelas múltiplas desigualdades; são muitas vezes 
imbricadas de escolhas lexicogramaticais que visibilizam, de modo mais ou menos engajado, revoltas com as indiferenças e com a desumanização promovida em relações sociais particulares e localizadas institucionalmente, ou não. São ações e interações que se materializam em diversos gêneros discursivos, que se delineiam a partir de estilos diversos e de vozes também diversas - isso implica considerar, então, que as práticas sociodiscursivas de resistência podem ser motivadas por outros discursos, pela tensão entre enunciados e/ou práticas que, semanticamente, se chocam em embates ideológicos nos quais quem as produz geralmente visa à promoção da não violência, do bem-estar social e das transformações sociais.

\section{PRÁTICAS SOCIODISCURSIVAS DE RESISTÊNCIA NOS RELATOS DE HOMENS TRANS ESTUDANTES}

Considerando a proposta da ADCG de Gomes (2020) para observar e analisar as práticas sociodiscursivas de resistência, a análise empreendida aqui será desenvolvida em três momentos com o intuito de responder às questões: Se os corpos transmasculinos resistem aos banheiros generificados da escola, quais são os poderes causais que motivam essas re(ações) discursivas? O que motiva corpos transmasculinos a produzirem práticas sociodiscursivas de resistência em práticas socioescolares e familiares? Quais foram os efeitos das práticas de resistência empreendidas pelos corpos transmasculinos nas atividades materiais da Escola João Nery?

\subsection{0 corpo transmasculino no banheiro escolar}

Neste primeiro momento, serão analisados os discursos que mencionam um espaço externo à sala de aula: o banheiro. Poderia esse local afetar o bem-estar social de estudantes trans, inserindo regulações e obstruções na vida escolar deles? Os banheiros, geralmente, são estruturas arquitetônicas generificadas que, além de normatizar práticas e corpos, podem ser cenário de interpelações violentas — sejam elas simbólicas ou físicas. Um homem trans em transição possui um corpo tanto com traços de masculinidades, quanto de feminilidades e, por isso, pode ser questionado, julgado e violentado no banheiro masculino (Cf. RIBEIRO, 2020, p.142).

Arthur menciona a forma como experiencia a vida escolar incluindo, entre outras informações, a relação que tem com o espaço do banheiro:

(1) Ser trans na escola é... é desafiador porque... por ter muito desconforto em estar no banheiro feminino, muitas vezes eu não vou ao banheiro [...]. Isso poderia me dar algum 
problema de saúde e, justamente por isso, eu conversei com eles pra ter autorização pra usar o da supervisão. Hoje em dia eu uso o banheiro da supervisão somente (Arthur).

O impasse de ser um estudante trans na escola é representado a partir de uma metáfora (é desafiador). O uso do termo "desafiador" é, mais precisamente, uma metáfora conceitual (LAKOFF; JOHNSON, 2002) que sugere semanticamente um contexto de disputa, de jogo ou guerra entre agentes sociais e estrutura material da prática socioescolar particular em que Arthur se encontra. Tal escolha metafórica, juntamente a outros elementos semióticos, mapeia discursivamente a forma como o estudante experiencia a vida escolar indicando práticas discursivas e não discursivas que o violentam. Ao empregar tal metáfora, ele avalia negativamente a vida escolar e segue identificando a causa dessa valoração (porque/por), a qual está associada ao grande desconforto (muito) que sente para usar o banheiro feminino. Esse sentimento deve-se à sua autoidentificação com o gênero masculino, ou seja, ao efeito de sentido que ele constrói com seu corpo ao performatizar sua transmasculinidade, isto é, ele se sente homem e não se sente confortável para frequentar um espaço demarcado como feminino. É interessante observar que o jovem não faz menção à possibilidade de uso do banheiro masculino - local que poderia oferecer riscos a ele uma vez que os sanitários masculinos são predominantemente frequentados por cismasculinidades, ditas hegemônicas, as quais geralmente são mais inclinadas à produção de práticas violentas, limitantes e preconceituosas contra a população trans.

Brito (2018) discute essa subalternização a partir do conceito de "masculinidade normalizadora" quando observa as violências produzidas por homens cis contra pessoas LGBTQI+ na educação física escolar, prática que pode ser transferida para o espaço do banheiro masculino de modo a promover insegurança nos homens trans impedindo-os de usá-lo. Com alto grau de engajamento, Arthur diz não frequentar o banheiro feminino (muitas vezes eu não vou ao banbeiro) e inclui um possível efeito disso em sua qualidade de vida (Isso poderia me dar algum problema de saúde) - já que deixar de fazer suas necessidades fisiológicas no longo período de tempo que passa na escola pode impactar o bom funcionamento de seu corpo. Ao deixar de ir ao banheiro (atividade material) na prática socioescolar o corpo trans pode, além de experienciar problemas físicos de saúde, vivenciar violências psicológicas/simbólicas - aquelas violências invisíveis que se delineiam essencialmente pelas vias da comunicação, da linguagem verbal, visual e corporal (BOURDIEU, 2003).

A prática sociodiscursiva de resistência se delineia na negociação para o uso do banheiro da supervisão. Em uma relação assimétrica de poder, em que a instituição escolar estabelece regulações, essa foi uma solução discursivamente buscada pelo jovem trans (eu conversei com eles pra ter autorização pra usar o da supervisão) e 
concedida pela equipe escolar (eles). Arthur, quando emprega os circunstanciadores temporal (boje) e de restrição (somente) na oração material (Hoje em dia eu uso o banheiro da supervisão somente), comprova ter conseguido a autorização para o uso daquele espaço evidenciando que sua agência foi transformacional, provocou mudanças na atividade material das práticas nesta escola.

Entretanto, essa autorização foi facilitada somente porque antes de Arthur, Bear Lukas já havia relatado à equipe da supervisão seu desejo de usar outro banheiro que não fosse o utilizado pelos demais estudantes. Ele foi o primeiro estudante trans da instituição a fazer essa reivindicação e a usar o banheiro da supervisão. $\mathrm{Na}$ entrevista, Bear nos disse:

(2) Eu nunca usei o banheiro masculino da escola, nunca entrei lá. Eu uso o perto da diretoria.

[...] Tive que fazer um rolo danado, porque eles ficaram relutando um pouco (Bear Lukas).

Bear afirmou categoricamente, de maneira repetida, não ter usado o banheiro masculino (nunca) e se identifica como o agente responsável por solicitar à escola o acesso a outro espaço para fazer suas necessidades fisiológicas (tive que fazer um rolo danado). O processo fazer, antecedido por modalização deôntica (tive), revela um alto grau de comprometimento com o que é dito - ele se viu em uma condição de vulnerabilidade na qual foi obrigado a agir. No contexto, fazer é um processo metafórico verbal - foi discursivamente que ele expôs à equipe da direção a sua demanda. Ele relatou também que as/os profissionais da educação não se dispuseram, proativamente, a acolher e solucionar sua necessidade (eles ficaram relutando). Esse processo mental iterativo (re-lut-ando), no gerúndio, comprova a corriqueira negligência de funcionárias/os da escola diante da necessidade que Bear tinha de frequentar um banheiro onde se sentisse seguro e confortável. É a partir dessas repetidas condutas de indiferença que a violência de gênero e a transfobia são reiteradas em práticas socioescolares afetando o bem-estar social de estudantes trans.

Essa iterabilidade da violência que, neste caso, é velada, silenciosa e invisível, pois se dá pela não ação (não falaram nada, esqueceram) ou pela falta de escuta ativa e empática de funcionários/as da escola, emerge sofrimentos e outros sentimentos que motivam a produção de práticas sociodiscursivas de resistência por parte dos estudantes trans. Como observamos em (2), Bear empregou uma expressão metafórica modalizada (rolo danado) que marca em seu relato a difícil negociação entre ele e a equipe escolar acerca do uso do banheiro da supervisão. $\mathrm{O}$ trecho seguinte enfatiza a morosidade - relutaram por um mês: 
(3) Passou um mês e eles não falaram nada, eles esqueceram. Até que eu fui lá de novo, perguntei e aí eles só falaram assim: "não... tá bom...cê pode usar, só vai lá na diretora avisar isso pra ela". Foi como se eles tivessem cansados de me enrolar e falaram pra mim usar normal (Bear Lukas).

Ainda que negligenciado, Bear persistiu (fui lá de novo). Na afirmação categórica, o modalizador (de novo) evidencia a resistência do estudante assim como o processo verbal (perguntei) - ele demonstrou várias vezes o interesse por frequentar um banheiro, direito básico que os demais estudantes possuem. Ele age dessa maneira em função da banalização que é dada à sua requisição uma vez que avalia negativamente parte da equipe escolar ao denunciar a falta de ação deles (eles esqueceram). Ademais, o estudante inclui em discurso indireto a voz da equipe pedagógica (eles só falaram assim: "não, tá bom... cê pode usar") e acaba, mais uma vez, valorando negativamente tais profissionais - isso porque Bear denuncia o descaso dessas pessoas que, sabendo de sua solicitação há mais de um mês, não repassaram à diretora e orientaram ele a informá-la (vai lá na diretora avisar isso pra ela).

Essa depreciação da conduta profissional da equipe pedagógica é, ainda, reiterada pelo léxico (normal), que representa a naturalização do descuido experienciado por Bear enquanto corpo transmasculino subalterno, abjeto e vulnerável. Apesar de o banheiro da direção ter sido uma alternativa que atendeu às necessidades fisiológicas e ontológicas de Bear e de Arthur, seus corpos foram submetidos a um regime de vigilância, já que passaram a frequentar um espaço que é ocupado por funcionários da escola, os quais estão em uma relação de poder mais privilegiada que eles. Outra implicação que a tal solução representa é a omissão da instituição em propor intervenções educativas sobre gêneros e sexualidades para conscientizar a comunidade escolar sobre a importância de respeitar estudantes trans nos banheiros do gênero com o qual se identificam - o que a longo prazo poderia fissurar ideologias conservadoras e mitigar práticas violentas e preconceituosas contra esses estudantes favorecendo o uso do banheiro escolar masculino (FAIRCLOUGH, 1992; FOUCAULT, 2014; Cf. RIBEIRO, 2020).

\subsection{0 corpo transmasculino nas relações socioescolares e familiares}

Ao relatar como é ser trans na vida escolar, Arthur nos disse o seguinte:

(4) [...] É ser forte! Até porque às vezes é como as pessoas dizem como se você não merecesse estar nesse espaço e... você vem todos os dias e você demora a entender que esse espaço também é seu. (Arthur, grifos nossos) 
Ele afirma categoricamente que ser trans na escola é ser forte evidenciando em seu discurso a necessidade constante de resistência - fato associado à crença socialmente cristalizada e apontada por ele de que a escola não é lugar de pessoas trans (as pessoas dizem como se você não merecesse estar nesse espaço). Por meio da articulação de um processo relacional com outro existencial (é ser) seguido do atributo (forte) ele produz uma avaliação de estima social da vida escolar revelando que seu corpo trans (des) ordena as normas de gênero daquela estrutura ao passo que tende a ser experienciado por parte das pessoas como "anormal" - por isso é preciso ser forte. Também por isso é preciso resistir por meio da constante presença no espaço escolar (você vem todos os dias), ainda que a escola seja um espaço de colisões de identidades hegemônicas e subalternas que produzem violências de gênero diariamente. Arthur não se identifica como alguém que "é" forte, ele precisa "ser forte" todos os dias na prática escolar potencialmente cis-heteronormativa em que se encontra (FAIRCLOUGH, 2003; WHITE, 2004; Cf. RIBEIRO, 2020; GOMES, 2020).

Bear Lukas nos relatou o enfrentamento de uma prática violenta que tem como agente um professor que negligenciou a sua identidade de gênero masculina afrontando sua existência trans por meio de violência verbal:

(5) Eu já tive um problema com um professor de História esse ano e ele só começou a me chamar de Lukas quando eu troquei na supervisão o meu nome [...] mesmo depois que eu mudei ele ainda ficava naqueles pronomes meio que femininos, tipo ficava me chamando de Senhorita Lukas (Bear Lukas).

O relato não inclui o nome do professor, apenas atribui a ele a disciplina que leciona. Essa escolha linguística pode estar associada à relação assimétrica de poder entre professor-estudante, fato que pode ter gerado em Bear um receio de ter sua entrevista publicizada e, com isso, vir a sofrer algum tipo de ameaça. Em (5) podemos notar, mais uma vez, que a escola não é um local que favorece o bem-estar social, a segurança e a autoestima do jovem estudante. Ele avalia negativamente a conduta desse professor quando particulariza o impasse (um problema) experienciado por este corpo. Na sequenciação avaliativa (ele só começou a me chamar de Lukas quando eи troquei na supervisão o meи nome), Bear evidencia o longo período de tempo que sua masculinidade foi invisibilizada e não reconhecida. Somente quando houve a formalização do nome do estudante na lista de chamada que o professor o nomeou de "Lukas", mas ainda assim permaneceu insultando discursivamente, de maneira irônica, sua identidade de gênero (Senhorita Lukas). Práticas discursivas como essa são esvaziadas de ética, de moralidade, de humanidade; não deveriam ser reiteradas por nenhum cidadão, jamais por um professor (FAIRCLOUFH, 2003; Cf. RIBEIRO, 2020). 
As violências de gênero produzidas nas práticas socioescolares somam-se a outro contexto da vida de Bear: o familiar. O estudante além de resistir a relações sociais que apagam e insultam sua vivência trans na escola, como analisamos em (5), também experiencia a deslegitimação de sua masculinidade em casa:

(6) [...] minha mãe ela não aceita, já tentei falar com ela várias vezes sobre isso. Ela tem a religião dela, [...] ela acha que isso é... é coisa do diabo. [...]. Todas as provas que eu assinava e que eu assino com o nome social eu escondia dela e até hoje eu não, eu não deixo ela ver, porque é sempre um escândalo, sempre querendo vir na escola [...]. Isso atrapalha muito na escola. (Bear Lucas)

As práticas sociodiscursivas de resistência estão presentes nos relatos de várias maneiras. Ora ocorrem por meio do discurso oral, ora por intermédio da linguagem escrita. Ao optar por continuar assinando as avaliações escolares com seu nome social, Bear enfrenta a mãe, que se recusou a reconhecer sua masculinidade em vários momentos (várias vezes). A recorrência do processo material assinar (assinaval assino), no pretérito e no presente, respectivamente, marcam a resistência do estudante em função do perfil religioso da mãe. Apesar de a progenitora desaprovar a identidade de gênero do filho e de demonizá-la (é coisa do diabo), ele segue construindo sua masculinidade, ainda que precise esconder suas provas assinadas com o nome social. A mãe, além de impedir o jovem estudante de ser quem é, isto é, coibir sua liberdade, intimida Bear fazendo com que ele não se sinta seguro para compartilhar sua vida escolar com ela. Essa relação conflituosa afeta o bem-estar emocional de Bear e atenua significativamente (muito) seu rendimento escolar (Isso atrapalba muito na escola). Por fim, observamos, então, que o discurso denunciativo de Bear representa a crença religiosa da mãe (o poder causal) como algo que dificulta o reconhecimento de sua identidade de gênero no âmbito familiar. Ao demonizar a performance transmasculina do menino, a mãe desmoraliza a existência dele e atribui características negativas que aproximam o corpo de Bear do profano e o distancia do sagrado (FAIRCLOUGH, 2003; Cf. RIBEIRO, 2020).

Ainda relatando sobre a vida familiar, Bear atribui à mãe, para além de ideologias religiosas, outras que assolam sua vivência transmasculina negra. Tal fato pode se explicar, principalmente, pela colisão dos diferentes eixos da diferença (raça/transgênero) presentes no corpo de Bear e representados em seu relato. Ele segue denunciando as opressões que vivenciou e, ao avaliar o futuro, prevê outras:

(7) [...] meu cabelo era cacheado, mas depois ele ficou liso, porque minha mãe obrigou e... me obrigou a alisar o cabelo. Por eu ser negro, e ... por ser trans, também, eu vou sofrer muitas questões, porque as pessoas têm muita, dessa coisa de, você só é homem se você tiver um pênis e essas coisas. Eu sei que eu vou sofrer pra caramba [...] (Bear Lukas). 
O enunciado men cabelo era cacheado resgata um traço identitário de Bear ligado à sua negritude. $O$ relato do jovem evidencia a mitigação da agência sobre seu próprio corpo, o que é marcado pela passivização (minha mãe me obrigou a alisar o cabelo). Esse processo de alisamento capilar forçado, além de produzir um apagamento da ancestralidade, submete o corpo negro e transmasculino de Bear a um parcial branqueamento e a uma tentativa de estetização para a feminilidade. Carvalho e Costa (2020, p. 55) defendem ainda que em se tratando dos corpos negros, o cabelo "é alvo das pressões sociais para o atendimento a um padrão de beleza extremamente claro e liso", ou seja, Bear não é vítima apenas dos dispositivos da racialidade e da cis-beteronormatividade, mas também do dispositivo da beleza eurocêntrica; e dos dispositivos pedagógico e religioso - como analisamos em (5) e em (6).

Os elementos lexicogramaticais negro e trans são empregados no relato de Bear em função semântica de causa - esses marcadores da diferença são tomados por ele como fatores motivadores para prever o alto grau de insegurança social quanto ao futuro (vou sofrer pra caramba). Ele segue problematizando o falocentrismo intrínseco às práticas sociais potencialmente cis-heteronormativas para legitimar o gênero (as pessoas têm muita, dessa coisa de você só é homem se você tiver um pênis). O circunstanciador "só" e o operador argumentativo condicional "se" são empregados para restringir a legitimidade da categoria homem à condição material mencionada - "ter um pênis". Ser um homem de vagina, então, torna o corpo transmasculino de Bear passível de questionamentos e de violências; não é um corpo inteligível.

Esse discurso sobre a materialidade do gênero que circula amplamente na vida social contribui para a manutenção da hegemonia cis-heteronormativa, afinal, trata-se de um (des)conhecimento que restringe a masculinidade à presença de um pênis no corpo. Essa concepção, como Bear provocou, é universalizante e gera estigmatização dos corpos transmasculinos que constroem a masculinidade por atos performativos e por estilizações corpóreas nem sempre marcadas por intervenções cirúrgicas.

Bear reconhece interseccionalmente a vulnerabilidade de seu corpo dentro da matriz de dominação: por ser negro e por ser trans. Ao mobilizar esses eixos, sua imbricação, se coloca como parte de um fenômeno social mais amplo e complexo: a experienciação de uma vida mais precária na estrutura social de hegemonia branca e cis (CRENSHAW, 2002; FAIRCLOUGH, 2003). Por que Bear afirma assertivamente que vai sofrer pra caramba? Para discutir essa previsão do futuro inserida no discurso do estudante, observemos um recorte da entrevista de Leonardo Peçanha, professor, ativista e homem negro trans brasileiro: 
[...] depois que eu fiz a adequação e eu passei a ser lido como homem negro pela sociedade, o racismo mudou. Mesmo que exista o privilégio por ser homem, senti e sinto, que o homem negro é visto como o bandido, aquele rouba, que é marginal, que é ameaça e ameaçador, que é visto como uma virilidade inquestionável e a ligação cultural com o falocentrismo. Ou seja, enquanto homem negro trans, eu deixei de ser objeto para ser ameaça (Portal Geledés, 2015, on-line).

O relato de Peçanha mostra as semelhanças entre a sua experiência de corpo transmasculino negro e o de Bear Lukas. Aquela insegurança identificada por Bear em seu relato se alinha ao fato do corpo de um homem negro trans poder ser interpretado socialmente como uma ameaça. O sofrimento futuro, relatado de forma ansiosa por Bear, estaria associado a possíveis questionamentos de sua virilidade enquanto homem de vagina? Estaria essa insegurança vinculada também ao receio de poder ser vítima de violência policial, já que não raramente seu corpo é identiifcado como criminoso por uma parte da sociedade que é racista? (Cf. RIBEIRO, 2020).

Ainda que o trecho (7) não apresente práticas sociodiscursivas de resistência, ele visibiliza linguisticamente traços corpóreos que tornam o corpo de Bear subordinado às masculinidades hegemônicas. Ao relatar seu sentimento de insegurança atrelado a características de seu corpo, o estudante evidencia, de maneira reiterada e intensificada (vou sofrer muitas questões / eu sei que vou sofrer pra caramba) a necessidade de resistência em momentos futuros de sua vida social.

A sua experiência corpórea, dessa forma, nesta prática socioescolar, é, ao mesmo tempo, opressão-luta-resistência. Seu corpo/discurso é protagonista, é agente desta luta-resistência à opressão executada pela matriz de dominação; é um corpo resistente que não evadiu do espaço escolar, apesar de todas as experiências reais de violência a que foi submetido. Bear e Arthur são dois corpos/discursos resistentes que criaram condições alternativas para suas vivências. Na constituição dessa prática socioescolar específica, embora subordinados, subalternizados e oprimidos pelas violências produzidas contra eles, os corpos trans estudantes intersecionados reagem ao interagir com outras pessoas em relações de poder hierarquizadas produzindo práticas discursivas de luta e de resistência para o reconhecimento das suas existências, isto é, para a significação de seus corpos enquanto corpos que importam; que almejam uma vida digna.

\section{REFLEXÕES SOBRE A ANÁLISE: EXPLANATÓRIA CRÍTICA}

A análise linguístico-discursiva desenvolvida evidenciou diferentes obstáculos que afetam o bem-estar e a dignidade da vida escolar de Arthur e de Bear Lukas. 
Conforme sugere Gomes (2020), ao observar os corpos interseccionados como elementos constituintes da prática social particular (vida escolar), identificamos conflitos associados a diferentes momentos discursivos os quais se mesclam dialeticamente. A presença do corpo interseccionado transmasculino no espaço escolar potencializa alterações e tensões de atividades materiais, relações sociais, fenômenos mentais (crenças, valores e ideologias) e discursos sobre eles e acerca de suas demandas físicas e simbólicas.

A atividade material refere-se aos espaços físicos e à materialidade das coisas. Nos relatos, enquanto agentes sociais engajados em mudanças, corpos transmasculinos produziram discursos de resistência que atuaram como poderes causais nas práticas socioescolares. O efeito disso veio à tona somente depois que Bear persistiu muito e conseguiu alterar a dinâmica do uso de um espaço físico da escola: o banheiro da supervisão. Outra modificação que o potencial de agência desse estudante reivindicou foi a materialização do nome social nas listas de chamada, o que tende a favorecer o reconhecimento e a legitimação de sua masculinidade, salvo quando algum professor seja por desconhecimento seja por desumanidade negligencia tal fato, como ocorreu com Bear, que foi vítima de insulto transfóbico promovido por um professor.

As relações sociais experienciadas pelos homens trans estudantes são, como relatou Bear, perpassadas de tensões - ainda mais quando envolvem negociações para o uso de um banheiro diferente dos utilizados pelos demais estudantes. Uma outra prova disso é a identificação que Arthur faz da vida escolar na oração existencial "ser trans na escola é ser forte". Afinal, ele não se sente pertencente ao espaço escolar devido à crença cristalizada socialmente de que a escola não é para vidas trans - fenômeno mental. Já a religiosidade da mãe de Bear e o possível conservadorismo do professor que o violentou verbalmente marca no discurso dele ideologias que são materializadas em práticas discursivas que o insultam.

Fairclough $(2019$, p. 31) argumenta que "a crítica acadêmica, por si mesma, não pode modificar a realidade". Entretanto, enquanto pesquisadores-educadores, podemos promover ações que almejem mudanças sociais. Sob essa perspectiva, planejamos e oferecemos aos profissionais da Escola João Nery um minicurso de formação continuada que objetivou promover um letramento de gêneros sociais, sexualidades e interseccionalidade -16 pessoas professoras/es participaram da atividade. Nossa ação transformacional, enquanto prática discursiva educativa, pode ter contribuído para alguma mudança nas atividades mentais (crenças, valores, ideologias) daqueles que participaram do minicurso, tornando mais emancipatórias, respeitosas e acolhedoras 
futuras relações sociais entre educadores/as e estudantes LGBTQI+de diferentes raças e/ou etnias (Cf. RIBEIRO, 2020).

\section{REFERÊNCIAS}

AKOTIRENE, C. (2019). Interseccionalidade. São Paulo: Editora Pólen.

ALMEIDA, G. (2012). 'Homens trans': novos matizes na aquarela das masculinidades? Revista Estudos Feministas. v. 20, n. 2, p. 513-523.

ARCHER, M. et al. (2004). Critical Realism: Essential Readings. London. New York: Routledge.

ÁVILA, S.N. (2014). FTM, transhomem, bomem trans, trans, bomem: A emergência de transmasculinidades no Brasil contemporâneo. Tese de Doutorado em Ciências Humanas. Pós-graduação Interdisciplinar em Ciências Humanas. Universidade Federal de Santa Catarina, Florianópolis.

BARROS, S. M. (2015). Realismos crítico e emancipação bumana. Campinas, SP: Pontes Editores.

BARROS, S. Mi VIEIRA, V. RESENDE, V. M. (2016). Realismo crítico e análise de discurso crítica: hibridismos de fronteiras epistemológicas. Polifonia. Cuiabá, v. 23, n. 33 , p. 11-28.

BENTO, B. (2011). Na escola se aprende que a diferença faz a diferença. Revista Estudos Feministas. v. 19, n. 2, p. 549-559.

BHASKAR, R. (1989). The possibility of Naturalism: a philosopbical critidue of the contemporary Human Sciences. Hemel Hempstead: Harvester Wheatsheaf.

BOURDIEU, P. (2003). A dominação masculina. Rio de Janeiro, RJ: Bertrand Brasil.

BRITO, L.T. (2018). "Bicha não jogava no time deles": Problematizando a masculinidade normalizadora na educação física escolar. VII Seminário Corpo, Gênero e Sexualidade. Disponível em: https://7seminario.furg.br/images/arquivo/143.pdf Acesso em: 20 ago. 2020.

BUENO, W. (2019). Repensando a interseccionalidade. Portal Geledés, 24 mai. 2019. Disponível em: https://www.geledes.org.br/repensando-a-interseccionalidade/ Acesso em: 10 de ago. 2020.

BUTLER, J. (2015). Relatar a si mesmo. Belo Horizonte: Autêntica. 
BUTLER, J. (2016). Problemas de gênero: feminismo e subversão da identidade. Rio de Janeiro: Editora Record.

BUTLER, J. (2018). Quadros de guerra: quando a vida é passível de luto. Rio de Janeiro: Civilização Brasileira.

CARVALHO, A. B. COSTA, J.C. (2020). Interseccionalizando a Análise de Discurso Crítica: a encruzilhada nos estudos discursivos e de gênero social. In: Gomes, M. C. A.; Vieira, V. C.; Carvalho, A. B. (org.), Práticas sociais, discurso, gênero social: explanações sobre a vida social. Curitiba: Appris Editora, p. 55-76.

CHOULIARAKI, L.; FAIRCLOUGH, N. (1999). Discourse in late modernity: Retbinking Critical Discourse Analysis. Edinburgh: Edinburgh University Press.

COLLINS, P.H. (2017). Se perdeu na tradução? Feminismo negro, interseccionalidade e política emancipatória. Parágrafo. v.5, v.1, p.7-17.

COLLINS, P.H. BILGE, S. (2016). Intersectionality. Cambridge: Polity Press.

CONNELL, R. (2016). Gênero em termos reais. São Paulo: nVersos.

CONNELL, R.; MESSERSCHMIDT, J. W. (2013) Masculinidade hegemônica: repensando o conceito. Revista Estudos feministas. v.21, n. 1, p. 241-282.

CONNELL. R. Prefácio (2013). In: Connell, R. Gênero em termos reais. São Paulo: nVersos, 2016, p. 16-21.

CRENSHAW, K. (2002). Documento para o encontro de especialistas em aspectos da discriminação racial relativos ao gênero. Revista Estudos Feministas. v. 10, n. 1, p. 171-188.

CRUZ, E. F. (2011). Banheiros, travestis, relações de gênero e diferenças no cotidiano da escola. Revista Psicologia Política. v. 11, n. 21, p. 73-90.

DUARTE, R. (2002). Pesquisa qualitativa: reflexões sobre o trabalho de campo. Cadernos de Pesquisa. Rio de Janeiro, n. 115, p. 139-154.

FAIRCLOUGH, I.; FAIRCLOUGH, N. (2012) Political discourse analysis. A method for advanced students. London: Routledge.

FAIRCLOUGH, N. (1992). Discurso e mudança social. Tradução de Maria Izabel Magalhães. Brasília: UnB, 2001. 
FAIRCLOUGH, N. (2003). Analysing discourse: textual analysis for social research. London, New York: Routledge.

FAIRCLOUGH, N. (2019). Análise Crítica do Discurso como raciocínio dialético: crítica, explanação e ação. Tradução de Maycon Silva Aguiar. Policromias. v. 4, n. 2, p. 32-50.

FATIMA, W. (2018). As sexualidades mal ditas no discurso religioso neopentecostal. Dissertação de Mestrado em Linguística. Universidade Federal Fluminense, Niterói.

FONSECA, C. (2010). O anonimato e o texto antropológico: dilemas éticos e políticos de etnografia "em casa". In: Schuch, P.; Vieira, M. S.; Peters, R. (org.), Experiências, dilemas e desafios do fazer etnográfico contemporâneo. Porto Alegre, Editora da UFRGS, p. 206-227.

FOUCAULT, M. (2014). Vigiar e punir. Rio de Janeiro: Vozes.

FRANCO, N.; CICILLINI, G. A. (2016). Travestis, transexuais e transgêneros na escola: um estado da arte. Cadernos de Pesquisa, v. 23, n. 2, p. 122-137.

GOMES, M.C.A. (2020). Propondo uma abordagem de Análise de Discurso Crítica Generificada. In: Gomes, M. C. A.; Vieira, V. C.; Carvalho, A. B. (org.), Práticas sociais, discurso, gênero social: explanações sobre a vida social. Curitiba: Appris Editora. p. 77-100.

HALLIDAY, M. MATTHIESSEN, C. (2004). An introduction to functional grammar. 3. ed. Londres: Arnold.

LAKOFF, G.; JOHNSON, M. (2002). Metáforas da Vida Cotidiana. Campinas: Mercado de Letras. São Paulo: Educ.

LUCON, N. (2015). Homens trans negro, Leonardo Peçanha diz: "Deixei de ser objeto para ser ameaça". Portal Geledés, 15 dez. 2015. Disponível em https://www.geledes. org.br/homem-trans-negro-leonardo-pecanha-diz-deixei-de-ser-objeto-para-serameaca/ Acesso em: 12 ago. 2020.

LUGONES, M. (2014) Rumo a um feminismo descolonial. Revista Estudos Feministas. v. 22, n. 3, p.935-952.

MISKOLCI, R. (2009) A teoria queer e a sociologia: o desafio de uma analítica da normalização. Sociologias. v. 11, n. 21, p. 150-182.

MOSCHKOVICH, M. (2015) Traduzir Raewyn Connell. In: Connell, R. Gênero em termos reais. (2016). São Paulo: $\mathrm{nVersos,} \mathrm{p.} 15$. 
NERY, J.W. GASPODINI, I. B. (2015). Transgeneridade na escola: estratégias de enfrentamento. In: Souza, R.M. (org), Coletânea Diversas Diversidades. Niterói: Cead. Universidade Federal Fluminense, ${ }^{\text {a }}$ ed. p. 61-81.

OLIVEIRA, A. L. G. (2015). "Somos quem podemos ser": os bomens (trans) brasileiros e o discurso pela (des) patologização da transexualidade. Dissertação de Mestrado em Ciências Sociais. Programa de Pós-Graduação em Ciências Sociais, Universidade Federal do Rio Grande do Norte, Natal.

PEDRINI, M. D. (2017). Homens trans(bordados): experiências juntas e misturadas na produção de outras masculinidades. Dissertação de Mestrado em Psicologia Institucional. Universidade Federal do Espírito Santo, Vitória.

RESENDE, V. M. (2008). Análise de Discurso Crítica e Etnografia: O Movimento Nacional de Meninos e Meninas de rua, sua crise e o protagonismo juvenil. Tese de Doutorado em Linguística. Programa de Pós-Graduação em Linguística, Universidade de Brasília, Brasília.

RESENDE, V. M. (2009). Análise de discurso crítica e realismo crítico: implicações interdisciplinares. Campinas: Pontes Editores.

RIBEIRO, S. D. S. (2020). Análise discursivo-crítica de relatos de bomens trans em práticas socioescolares de Viçosa-MG. Dissertação de Mestrado em Letras (Estudos Discursivos). Programa de Pós-Graduação em Letras, Universidade Federal de Viçosa, Viçosa-MG.

SALABERT, D. (2019). O que você faz com os seus privilégios?. Entrevista com Duda Salabert. Cadernos de Gênero e Diversidade. v.5, n.1, p.35-43. Disponível em: https://portalseer. ufba.br/index.php/cadgendiv/article/view/31921/18991 Acesso em: 23 ago. 2020.

SALES, A. (2012). Travestilidades e escola nas narrativas de alunas travestis. Dissertação de Mestrado em Educação. Universidade Federal de Mato Grosso, Rondonópolis.

SAYER, A. (2000). Características-chave do Realismo Crítico na prática: um breve resumo. Estudos de Sociologia. v.2, n.6, p. 7-32.

TECRUZI, A. et al. (2017). Antologia trans. 30 poetas trans, travestis e não-binários. $1^{\text {a }}$ reimpressão. São Paulo: Cursinho Popular Transformação.

WHITE, P. (2004). Valoração - Linguagem da Avaliação e da perspectiva. Linguagem em (Dis) curso-LemD. v.4, n.esp, p.178-205.

Recebido: 1/9/2020

Aceito: $11 / 10 / 2020$

Publicado: 14/10/2020 